\title{
Wilms tumour: Long-term survival of patients treated at Mbingo Baptist Hospital in Cameroon between 2007 and 2012
}

\begin{tabular}{|c|c|}
\hline \multicolumn{2}{|c|}{$\begin{array}{l}\text { Authors: } \\
\text { Peter B. Hesseling }{ }^{1} \\
\text { Richard Bardin } \\
\text { James A. Brown } \\
\text { Comfort Kimbi } \\
\text { Heather Draper }^{2} \\
\text { Peter McCormick } \\
\text { Francine Kouya }{ }^{2} \text { (] }\end{array}$} \\
\hline $\begin{array}{l}\text { Affiliations: } \\
{ }^{1} \text { Department } \\
\text { and Child Hea } \\
\text { Hospital, Stell } \\
\text { University, Ca } \\
\text { South Africa }\end{array}$ & $\begin{array}{l}\text { f Paediatrics } \\
\text { th, Tygerberg } \\
\text { enbosch } \\
\text { e Town, }\end{array}$ \\
\hline $\begin{array}{l}{ }^{2} \text { Cameroon Ba } \\
\text { Convention H } \\
\text { (CBCHB), Mbi } \\
\text { Hospital, Nort } \\
\text { Cameroon, Ca }\end{array}$ & $\begin{array}{l}\text { ptist } \\
\text { alth Board } \\
\text { go Baptist } \\
\text { iwest } \\
\text { meroon }\end{array}$ \\
\hline $\begin{array}{l}{ }^{3} \text { Beryl Thyer } N \\
\text { Trust, Warkto } \\
\text { Kingdom }\end{array}$ & $\begin{array}{l}\text { lemorial Africa } \\
\text {, United }\end{array}$ \\
\hline $\begin{array}{l}\text { Correspondin } \\
\text { Peter Hesselin } \\
\text { pbh@sun.ac.z }\end{array}$ & $\begin{array}{l}\text { author: } \\
\text { g, } \\
\text { a }\end{array}$ \\
\hline $\begin{array}{l}\text { Dates: } \\
\text { Received: } 07 \text { J } \\
\text { Accepted: } 29 \\
\text { Published: } 26\end{array}$ & $\begin{array}{l}\text { une } 2019 \\
\text { Aug. } 2019 \\
\text { Nov. } 2019\end{array}$ \\
\hline $\begin{array}{l}\text { How to cite th } \\
\text { Hesseling PB, } \\
\text { JA, et al. Wilm } \\
\text { Long-term sur } \\
\text { treated at Mbi } \\
\text { Hospital in Can } \\
2007 \text { and } 2012 \\
2019 ; 3(0) \text {, a88 } \\
10.4102 / \text { sajo.v }\end{array}$ & $\begin{array}{l}\text { is article: } \\
\text { ardin R, Brown } \\
\text { tumour: } \\
\text { ival of patients } \\
\text { ggo Baptist } \\
\text { eroon between } \\
\text { S. Afr. j. oncol. } \\
\text { https://doi.org/ } \\
\text { 3i0.88 }\end{array}$ \\
\hline Read online: & \\
\hline 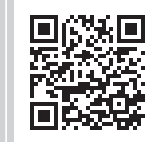 & $\begin{array}{l}\text { Scan this QR } \\
\text { code with your } \\
\text { smart phone or } \\
\text { mobile device } \\
\text { to read online. }\end{array}$ \\
\hline
\end{tabular}

Background: The survival rate of Wilms tumour (WT) in low-income sub-Saharan countries in Africa is below 50\%. Thirty-five consecutive children diagnosed with WT between 2007 and 2012 at Mbingo Baptist Hospital, Cameroon, were observed in this study and treated with a modified International Society of Paediatric Oncology (SIOP) treatment protocol.

Aim: Our objective was to achieve a significant overall cure rate in patients with WT.

Setting: This report describes the long-term outcome of patients treated at Mbingo Baptist hospital (MBH) in northwest Cameroon.

Method: This consisted of preoperative chemotherapy, nephrectomy and post-operative chemotherapy depending on the stages of the disease and histological findings. Radiotherapy was not available. The diagnosis and staging was based on abdominal ultrasound (US), chest $X$-Ray and the histological findings at nephrectomy and surgery and/or fine needle aspirate (FNA). The cohort included 17 boys and 18 girls with a median age of 3.5 years (range 6 months to 9 years). The surgical stage distribution was: stage I = 9; II = 3; III = 5; IV = 12; $\mathrm{V}=3$; undetermined $=3$ patients.

Results: Three guardians refused surgery; there were three deaths related to surgery and two deaths during preoperative chemotherapy. All relapses occurred within 12 months. The survival rate was significantly better in stages I and II than in stages III and IV of cancer. Two of the three patients with bilateral WT are long-term survivors. The overall projected survival rate after a median follow-up of 84 months (range $4-125$ months) was $44 \%$. One patient in remission was lost to follow-up after 4 months. All patients admitted with a diagnosis of WT were included in the Kaplan-Meier survival analysis.

Conclusion: With this treatment schedule followed for more than $50 \%$ of the patients, it can be concluded that obtaining consent from every guardian for nephrectomy and preventing deaths related to surgery and chemotherapy could improve the overall survival rate of all patients diagnosed with WT.

Keywords: Wilms tumour; SIOP protocol; long term survival; Cameroon; low-income country.

\section{Introduction}

The reported survival rate for Wilms tumour (WT) in low-income sub-Saharan countries varies from $0 \%$ to $46 \%$ when using preoperative chemotherapy, compared to more than $85 \%$ in high-income countries. ${ }^{1,2,3}$ This report describes the long-term outcome of patients treated at Mbingo Baptist hospital (MBH) in Northwest Cameroon. Cameroon is a low-income country with limited resources for cancer treatment. $\mathrm{MBH}$ had resident and visiting physicians and surgeons. The available supportive care in terms of blood products (only whole blood from an available donor pool), choice of antibiotics, parenteral feeding, microbiological cultures, an intensive care unit, infusion pumps and biochemistry investigations was limited during this study. Radiotherapy was not available. Imaging was limited or restricted to X-Rays and ultrasound (US). Drugs and hospitalisation were provided without cost, but parents had to contribute in part to the cost of surgery.

The only children's cancer treatment centre in Cameroon was the Chantal Biya Hospital in Yaounde, $350 \mathrm{~km}$ distance from $\mathrm{MBH}$, which in practice was inaccessible and unaffordable to the majority of patients. The community consists mainly of subsistence farmers with a monthly family cash income

Copyright: @ 2019. The Author(s). Licensee: AOSIS. This work is licensed under the Creative Commons Attribution License. 
of below \$50. Transport, with poor roads which become inaccessible in the rainy season, and limited access to mobile telephones, provided practical challenges to compliance with treatment and follow-ups. Our objective was to achieve a significant overall cure rate in patients with WT.

\section{Methods}

In this non-randomised prospective study, all patients who were admitted to $\mathrm{MBH}$ with a primary diagnosis of WT between January 2007 and October 2012 were included in the survival analysis. Guardians gave informed consent to participate in the study and ethical approval was obtained from the Cameroon Baptist Convention Health Board (CBCHB) institutional review board. Patient records were kept secure in the registry office.

The diagnosis was based on the clinical presentation, abdominal ultrasound (US) findings and in some fine needle aspirate (FNA).

A chest X-Ray was carried out to identify patients with pulmonary metastases and exclude them from this study. The final staging was based on the findings obtained during the surgery. Other routine investigations included a full blood count, malaria smear, urinalysis, faeces microscopy, HIV screening test, blood urea and creatinine level count. Guardians were supported with a daily ration of rice and $\$ 1$ in cash to purchase food to prepare meals for themselves and their child, and up to $\$ 20$ for local transport. Patients remained in hospital until surgery had been performed, and received a daily egg and a cup of formula milk as a supplement to their meals whilst in hospital. Surgery was performed by a resident under supervision by a faculty or visiting general surgeon, and pathology was reviewed by a resident pathologist according to the Society for Industrial and Organizational Psychology (SIOP) recommendations. The need for blood transfusion was either the level of haemoglobin below $7 \mathrm{gram} / \mathrm{dl}$ or active bleeding during surgery. Chemotherapy was delayed if the total white cell count (WCC) dropped below 1000/ $\mathrm{mm}^{3}$ Fever was defined as one episode of a temperature of equal to or exceeding 38.5 ${ }^{\circ} \mathrm{C}$, or two episodes of $38{ }^{\circ} \mathrm{C}$ within a 24 -h period. Malaria was immediately excluded and treated if present. Antibiotic treatment commenced immediately with gentamicin and ampicillin, followed by a cephalosporin if fever persisted. Follow-up examination within 1 year after the surgery included six monthly abdominal US investigations. Longterm follow-up was achieved by hospital visits, home visits by the research nurse and telephone calls.

A modified SIOP protocol was used. Preoperative chemotherapy in patients with localised disease consisted of intravenous injection of Actinomycin D $45 \mathrm{mcg} / \mathrm{kg}$ on days 1 and 15 and Vincristine $1.5 \mathrm{mg} / \mathrm{m}^{2}$ (maximum dose $2.0 \mathrm{mg}$ ) on days 1, 8, 15 and 22 followed by surgery. Patients with metastatic disease received Actinomycin D $45 \mathrm{mcg} / \mathrm{kg}$ on days 1 and 29, Doxorubicin $50 \mathrm{mg} / \mathrm{m}^{2}$ (intravenous bolus) on days 14 and 43 and Vincristine $1.5 \mathrm{mg} / \mathrm{m}^{2}$ on days $1,8,15,22$, $29,36,43$ and 50 followed by surgery. Stage V patients were given chemotherapy for as long as tumour shrinkage was evident on US, followed by kidney-sparing surgery if possible. Post-operative patients with surgical stage I with favourable histology received no further chemotherapy. Patients with unfavourable histology or a delay of more than 10 days to obtain histology results were given post-operative Actinomycin D and Vincristine on days 10 and 31.

Patients with surgical stages II and III received Actinomycin $\mathrm{D}$ and Vincristine on days 10, 31, 52 and 73 irrespective of the histology. Stage IV patients with resolved metastases were treated similar to stage III, and non-responders received palliative care. Palliative care consisted of counselling, nutritional advice, analgesic drugs and home visits if needed. Stage V patients received post-operative chemotherapy similar to stage III patients. All chemotherapy doses were reduced by one-third if the body weight was below $12 \mathrm{~kg}$.

\section{Ethical considerations}

This study was approved by the Institutional Review Board of the Cameroon Baptist Convention Health Board (no 2007-04).

\section{Results}

The age of the observed 17 boys and 18 girls ranged from 6 months to 9 years (median age 3.5 years). The surgical stage distribution was stage $\mathrm{I}=9 ; \mathrm{II}=3$; III $=5 ; \mathrm{IV}=12 ; \mathrm{V}=3$; unstaged $=3$ (these patients died without a surgical resection). The majority of patients were at advanced state of the disease (stages III, IV and V). Age, gender and stage distribution are illustrated in Table 1. WT was histologically confirmed in 31 patients at nephrectomy $(n=29)$ or with an FNA $(n=2)$. Tumour volume on US ranged from $67 \mathrm{~mL}$ to $2372 \mathrm{~mL}$ with the tumour volume exceeding $1000 \mathrm{~mL}$ in nine patients. There was one case each of anaplastic WT, renal cell carcinoma and cystic WT. Three guardians refused surgery despite

TABLE 1: Demographic and clinical characteristics of children treated with an SIOP using an adapted protocol in Cameroon between 2007 and $2012(N=35)$.

\begin{tabular}{|c|c|c|c|c|c|c|}
\hline Variables & $\begin{array}{c}\text { Total } \\
(n=350)\end{array}$ & $\%$ & $\begin{array}{c}\text { Died } \\
(n=20)\end{array}$ & $\%$ & $\begin{array}{c}\text { Alive } \\
(n=15)\end{array}$ & $\%$ \\
\hline Median age in years (IQR) & 3.5 & $2.5(5.0)$ & 3.5 & $2.5(4.5)$ & 4.0 & $2.0(5.0)$ \\
\hline Mean age in years (s.d.) & 3.7 & 1.7 & 3.4 & 1.4 & 4.0 & 2.0 \\
\hline Male gender (\%) & 17 & 48.6 & 7 & 35.0 & 10 & 66.7 \\
\hline Surgical stage (\%) & - & - & - & - & - & - \\
\hline I & 9 & 28.1 & 3 & 17.7 & 6 & 40.0 \\
\hline II & 3 & 9.4 & 0 & 0.0 & 3 & 20.0 \\
\hline III & 5 & 15.6 & 5 & 29.4 & 0 & 0.0 \\
\hline IV & 12 & 37.5 & 8 & 47.1 & 4 & 26.7 \\
\hline v & 3 & 9.4 & 1 & 5.9 & 2 & 13.3 \\
\hline $\begin{array}{l}\text { Median duration followed } \\
\text { in months (IQR) }\end{array}$ & 22 & $7.0(83.0)$ & 8.5 & $4.5(15.5)$ & 85 & $71.0(99.0)$ \\
\hline Unstaged Patients $\dagger$ & 3 & 8.6 & 3 & 8.6 & - & - \\
\hline
\end{tabular}

$I Q R$, interquartile range; s.d., standard deviation; SIOP, Society for Industrial and Organizational Psychology.

$\dagger$, Three patients were without surgical stage because they died before surgery. 
repeated counselling. No instance of tumour spillage during nephrectomy was reported. There were three surgery-related deaths - one after primary surgery, one a day after nephrectomy following preoperative chemotherapy and one from sepsis following a colostomy repair without proper preoperative bowel preparation whilst in remission.

Two deaths occurred during the preoperative chemotherapy phase, one from fluid overload and the other at home from an undetermined cause. The five patients with stage III disease died of:

- an unknown acute illness in Nigeria after 22 months

- after primary surgery on day 2

- septicaemia following a colostomy repair without preceding bowel preparation 10 months after completion of treatment

- progressive disease after 6 months

- relapse of the disease accompanied by pulmonary metastases after 8 months.

Two of the three patients with bilateral disease (stage V) are long-term survivors. One survivor had a left-sided nephrectomy, the other survivor refused surgery after preoperative chemotherapy. The patient who died had an unresectable bilateral tumour in a horseshoe kidney. All patients were HIV sero-negative. No tumour rupture or spillage was recorded during nephrectomy. One patient had primary surgery with complete removal of the tumour. The incidental diagnosis of malaria did not adversely affect the planned treatment.

The duration of follow-up in the 15 survivors ranged from 4 to 125 months (median 84 months). One patient with stage II disease with favourable histology, who was in remission after 4.3 months, was lost to follow-up. Overall survival was measured from the date of the diagnosis to the date of

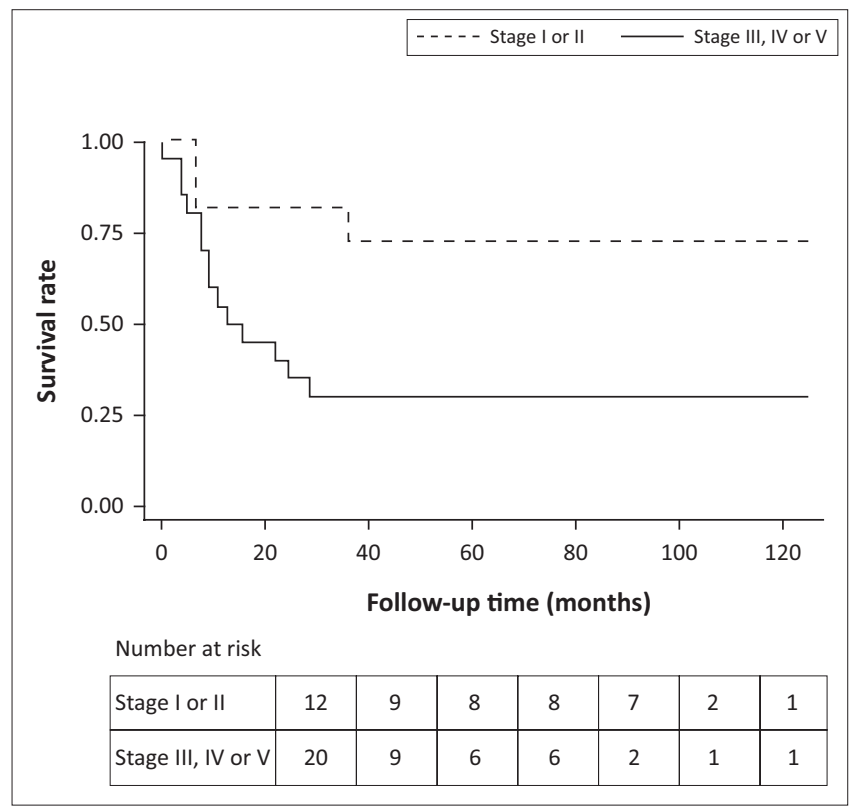

Note: Log-rank $p$-value $=0.0281$.

FIGURE 1: Kaplan-Meier overall survival estimate. treatment failure or the date of last follow-up. The Kaplan Meier analysis was performed for the overall survival rate for the entire cohort under study under each surgical stage. The overall survival rate in patients with limited and advanced disease is illustrated in Figure 1 and Figure 2. Patients who developed progressive disease or relapsed were offered palliative care. All relapses in patients, who had completed treatment and were in remission, occurred within 12 months. The long-term overall survival rate was $43 \%(n=15)$.

\section{Discussion}

Although this prospective study includes a relatively small number of patients, the $43 \%$ survival rate with a $96 \%$ longterm follow-up rate compares favourably with the $46 \%$ survival rate reported at Malawi. ${ }^{1}$ All patients who were admitted with the intent to treat, including stage $\mathrm{V}$ patients and the patient with renal carcinoma, were included in the survival analysis. The duration of post-operative chemotherapy for stages III and IV was shorter (73 days) than in Malawi (16 weeks). ${ }^{1}$ Patients in Kenya had a $41 \%$ survival rate, but received three drugs preoperatively (Actinomycin, Vincristine and Doxorubicin), and some stage III patients also received radiotherapy. ${ }^{2}$ The age and gender distribution was as expected in black African patients. ${ }^{4}$ The high incidence $(63 \%)$ of advanced state of the disease (stages III, IV, V) is higher than that recorded in South African black patients and similar to the reported rate in sub-Saharan low-income countries. The overall long-term survival in black patients in South Africa, which is a middle-income country, was $65 \%$, and this is similar to the rate in white patients and patients of mixed ethnicity. ${ }^{4}$

The results obtained in black patients and patients of other ethnic-groups were similar to the above when given the same treatment. ${ }^{5}$ The French African Paediatric Oncology group (FAPOG) reported a higher incidence greater than $70 \%$ in a two-year event free survival rate in patients from Francophone North African countries, but, patients with bilateral disease, patients who did not have a nephrectomy, patients who abandoned treatment and early deaths were excluded from their survival analyses. Fifty-seven per cent of the study patients were at stages I and II of the disease. ${ }^{6}$

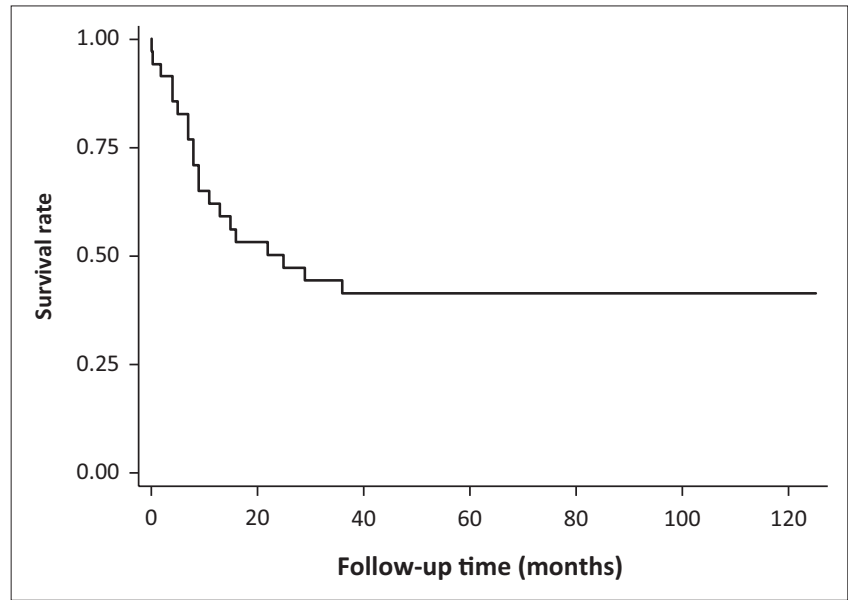

FIGURE 2: Kaplan-Meier survival by surgical stage estimate. 
The poor outcome in our stage III patients was partly because of potentially preventable deaths. There were no relapses beyond 12 months, and a two-year follow-up period therefore seems long enough to assess event free survival rate. This is supported by the other studies mentioned. Surgical expertise is an important factor. The main purpose of preoperative chemotherapy is to improve resectability and to reduce the risk of tumour spillage during surgery. No tumour spillage was recorded compared to $8 \%$ in patients in South Africa following primary surgery and $7 \%$ in patients after preoperative chemotherapy in the FAPOG series. ${ }^{7,8}$ The three surgical deaths could possibly have been prevented.

The low rate of abandonment of treatment (three patients refused surgery and one patient lost to follow-up) could be ascribed to extensive family counselling, free treatment (except for the cost of surgery) and the provision of food and money for transport. The refusal of three guardians to allow a nephrectomy, despite repeated counselling, was because of cultural beliefs and ignorance about cancer. As only the patient's weight on admission was routinely recorded, it was not possible to accurately report on the nutritional status.

Survival is related to the stage of the disease and its treatment. The indication of a very high rate of advanced stages in African patients in this and in other reports clearly underscores the urgent need to promote early diagnosis by advocacy to the population, and to train health workers to identify and to refer patients to a paediatric oncology service. Guidelines for the management of WT in low-income countries were published by SIOP PODC in $2012 .{ }^{9} \mathrm{MBH}$ now has a resident paediatric surgeon and an intensive care unit. We are currently participating in the collaborative African WT Pilot study, which applies SIOP PODC recommendations.

Early findings indicate that the rate of patients who are surviving free of cancer after completion of treatment in this study improved from $52 \%$ to $68 \%$, abandonment of treatment dropped from $23 \%$ to $13 \%$, and that the death rate during treatment dropped from $21 \%$ to $13 \%$ when compared to historical controls in the participating centres. ${ }^{10}$

\section{Conclusion}

It is possible to achieve a good cure rate in patients with WT even with limited resources. The lower cure rate in children with WT in low-income African countries can be improved if collaborative efforts are made by treatment centres, local governments and international agencies. This should include the promotion of early diagnosis and the provision of adequate resources for the diagnosis and treatment of this highly curable childhood cancer.

\section{Acknowledgements Competing interests}

The authors have declared that no competing interests exist.

\section{Authors' contributions}

All authors contributed equally to this work.

\section{Funding information}

Funding was provided by the Norwegian Parent Association for the drugs required for the Children with Cancer. The Beryl Thyer Memorial Africa Trust provided funding for the hospitalisation and the Swiss Cancer League provided funding for long term follow up and statistical analysis.

\section{Data availability statement}

Data sharing is not applicable to this article as no new data were created or analysed in this study.

\section{Disclaimer}

The views and opinions expressed in this article are those of the authors and do not necessarily reflect the official policy or position of any affiliated agency of the authors.

\section{References}

1. Israels $T$, Borgstein $E$, Pidinide $D$, et al. Management of children with a Wilms tumor in Malawi, sub-Saharan Africa. J Pediatr Hematol Oncol. 2012;34(8):606610. https://doi.org/10.1097/mph.ObOe3182580921

2. Njuguma F, Martijn HP, Kuremu RT, et al. Wilms tumor treatment: Perspectives from a low-income setting. J Glob Oncol. 2017;3(5):555-562. https://doi. org/10.1200/JGO.2016.0065389

3. Mwamba PM, Rogena E, Kitonyi GW. A ten year retrospective audit of the clinicopathological management and treatment outcomes of patients with nephroblastoma at Kenyatta National Hospital. American J Cancer Prev. 2017;5(2):21-24. https://doi.org/10.1269/ajcp-5-2-1

4. Stones DK, Hadley GP, Wainwright RD, Stefan DC. The impact of ethnicity on Wilms tumor characteristics and outcomes of a South African Cohort. Int J Pediatr. 2015. https://doi.org/10.1155/2015/706058

5. Visser YT, Uys R, Van Zyl A, Stefan DC. Nephroblastoma - A 25 year review of a South African unit. J Med Life. 2014;7(3):445-449.

6. Moreira C, Nasser M, Ziamati S, et al. Treatment of nephroblastoma in Africa: Results of the first French African pediatric oncology group (FPAOP) study. Pediatr Blood Cancer. 2011;58(1). https://doi.org/10.1002/pbc.23284

7. Davidson A, Hartley P, Rode H, Millar A. Wilms tumor experience in a South African centre. Pediatr Blood Cancer. 2006;46(4):465-447. https://doi.org/10.1155/ 2015/706058

8. Waldeab WE, Nyongole OV, Frank B. Wilm's tumor: Presentation and outcome at Kilimanjaro Christian Medical Centre. J Med Res. 2016;2(4):114-117.

9. Israels T, Moreira C, Scanlan T, Molyneux L, Kamonderi S, Hesseling P. SIOP PODC: Clinical guidelines for the management of children with Wilms tumor in a low income setting. Pediatr Blood Cancer. 2012;60(1). https://doi.org/10.1002/ pbc. 24321

10. Israels T, Paintsil V, Nyirenda D, et al. Improved outcome at end of treatment in the collaborative Wilms tumor Africa Project. Pediatr Blood Cancer. 2018;(5). https://doi.org/10.1002/pbc.26945 